\title{
Procalcitonin Levels in Gram-Positive, Gram-Negative, and Fungal Bloodstream Infections
}

\author{
Christian Leli, Marta Ferranti, Amedeo Moretti, Zainab Salim Al Dhahab, \\ Elio Cenci, and Antonella Mencacci
}

Microbiology Section, Department of Experimental Medicine, University of Perugia, 06100 Perugia, Italy

Correspondence should be addressed to Antonella Mencacci; antonella.mencacci@unipg.it

Received 30 November 2014; Revised 24 February 2015; Accepted 25 February 2015

Academic Editor: Olav Lapaire

Copyright (C) 2015 Christian Leli et al. This is an open access article distributed under the Creative Commons Attribution License, which permits unrestricted use, distribution, and reproduction in any medium, provided the original work is properly cited.

\begin{abstract}
Procalcitonin (PCT) can discriminate bacterial from viral systemic infections and true bacteremia from contaminated blood cultures. The aim of this study was to evaluate PCT diagnostic accuracy in discriminating Gram-positive, Gram-negative, and fungal bloodstream infections. A total of 1,949 samples from patients with suspected bloodstream infections were included in the study. Median PCT value in Gram-negative $(13.8 \mathrm{ng} / \mathrm{mL}$, interquartile range (IQR) 3.4-44.1) bacteremias was significantly higher than in Gram-positive $(2.1 \mathrm{ng} / \mathrm{mL}$, IQR $0.6-7.6)$ or fungal $(0.5 \mathrm{ng} / \mathrm{mL}$, IQR $0.4-1)$ infections $(P<0.0001)$. Receiver operating characteristic analysis showed an area under the curve (AUC) for PCT of 0.765 (95\% CI $0.725-0.805, P<0.0001)$ in discriminating Gram-negatives from Gram-positives at the best cut-off value of $10.8 \mathrm{ng} / \mathrm{mL}$ and an AUC of $0.944(95 \%$ CI $0.919-0.969, P<0.0001)$ in discriminating Gram-negatives from fungi at the best cut-off of $1.6 \mathrm{ng} / \mathrm{mL}$. Additional results showed a significant difference in median PCT values between Enterobacteriaceae and nonfermentative Gram-negative bacteria (17.1 ng/mL, IQR 5.9-48.5 versus $3.5 \mathrm{ng} / \mathrm{mL}$, IQR $0.8-21.5 ; P<0.0001)$. This study suggests that PCT may be of value to distinguish Gram-negative from Grampositive and fungal bloodstream infections. Nevertheless, its utility to predict different microorganisms needs to be assessed in further studies.
\end{abstract}

\section{Introduction}

Procalcitonin (PCT) is a 116-amino-acid peptide whose high levels are strongly associated with systemic bacterial infections $[1,2]$ and with the severity of illness [3]. It is produced in response to bacterial endotoxin and inflammatory host cytokines [4] and may help in discriminating bacterial from viral infections [4] and true bacteremia from contaminated blood cultures $[5,6]$. It is known that Gram-positive or Gram-negative bacteria or fungi activate different Toll-like receptor (TLR) signaling pathways, resulting in production of different proinflammatory cytokines that ultimately stimulate PCT release [7]. This notion suggests that different pathogens could lead to different levels of PCT production. This issue could be of particular relevance in bloodstream infections, in which PCT could assist clinicians in setting the most appropriate early therapeutic approach that is essential for patient outcome [8]. Indeed, an inappropriate initial antimicrobial therapy is an independent risk factor for adverse outcome in patients with bloodstream infections from Staphylococcus aureus $[9,10]$ or Gram-negatives [11, 12].

Few studies are available in the literature on PCT utility in differentiating among Gram-negative, Gram-positive, or fungal bacteremias [13-15]. The aim of the present study was to evaluate PCT ability to discriminate different bacterial or fungal etiology in a large population of patients with documented bloodstream infection.

\section{Materials and Methods}

2.1. Patients and Samples. This prospective observational study was conducted using clinical and routine laboratory data collected from the Clinical Microbiology Unit of the General Hospital of Perugia, Italy, from March to September 2014.

Inclusion criteria were unselected consecutive blood samples for blood culture (BC) and PCT that, according to our hospital standard protocol, were collected simultaneously 
from each patient with suspected sepsis, defined according to Bone et al. [16]. Only patients older than 18 years of age were included in the study. For each patient, only one bloodstream infection episode and, for each episode, only the first samples were considered. In the case of two or more episodes observed in the same patient, only the first was considered. A bloodstream infectious episode was defined as a time-period associated with one or more blood cultures positive for the same organism/organisms [17, 18]. Exclusion criteria were lack of at least one of the above samples or samples not drawn simultaneously from the same patient.

2.2. PCT Determination. PCT levels were measured in sera via the automatic analyser VIDAS B.R.A.H.M.S. PCT assay (bioMérieux, Marcy l'Etoile, France), according to the manufacturer's instructions. The lower limit of detection of the assay was $0.05 \mathrm{ng} / \mathrm{mL}$ and the functional assay sensitivity was $0.09 \mathrm{ng} / \mathrm{mL}$ (VIDAS B.R.A.H.M.S. PCT package insert; bioMérieux).

2.3. Blood Culture. For each sample, an aliquot of 5 to $10 \mathrm{~mL}$ whole blood was inoculated into BACTEC aerobic and anaerobic bottles (Becton Dickinson, Sparks, MD). BACTEC Plus bottles were used for patients under antibiotic therapy and standard bottles for untreated patients. Two sets from two different sites were collected at the same time. The bottles were incubated in a BACTEC FX automated blood culture system (Becton Dickinson). All bottles flagged positive were removed from the instrument and an aliquot was taken for Gram-stain and culture on solid media for subsequent analysis. Identification of microorganisms was performed with conventional methods and with the matrix-assisted laser desorption/ionization-time-of-flight mass spectrometry (Bruker Daltonics, Bremen, Germany).

2.4. Definition of Pathogen. Microorganisms detected by BCs were considered to be clinically relevant pathogens rather than contaminants according to the following conditions: (i) microorganisms identified by two or more BCs, reported by the clinician as the cause of the episode of sepsis; (ii) microorganisms detected by only one set of BCs if coincided with the results of culture from samples from the suspected infectious foci, collected from the same patient during the same infectious episode; (iii) microorganisms detected only in one set of BCs, belonging to a species included among the etiopathogenic agents of the patient infectious disease (e.g., Streptococcus pneumoniae from a patient with lobar pneumonia); (iv) microorganisms detected only in one set of BCs reported by the clinician as the cause of the episode of sepsis in the final diagnosis, based on clinical, instrumental, and laboratory data. Coagulase-negative staphylococci, Corynebacterium spp., and other skin commensals were considered contaminants when isolated from only one set of BCs [19] and in the absence of clinical and/or laboratory data suggesting their pathogenic role.

2.5. Statistical Analysis. Values were expressed as count and percentages or median and interquartile range (IQR). Statistical significance was assumed if a null hypothesis could
TABLE 1: Demographic and clinical characteristics of the 1,949 patients included in the study.

\begin{tabular}{lc}
\hline Variable & Values \\
\hline Males & $1,150(59 \%)$ \\
Females & $799(41 \%)$ \\
Age (years) & $74(\text { IQR } 62-83)^{*}$ \\
Ward of hospitalization & \\
$\quad$ Medical & $1,735(89 \%)$ \\
Surgical & $179(9.2 \%)$ \\
Intensive Care Unit & $35(1.8 \%)$ \\
Antimicrobial therapy before sampling & $1,553(79.7 \%)$ \\
Blood culture & \\
$\quad$ Negative & $1,286(66 \%)$ \\
Contaminated & $72(3.7 \%)$ \\
Monomicrobial & $586(30.6 \%)$ \\
Polymicrobial & $5(0.3 \%)$ \\
\hline
\end{tabular}

${ }^{*}$ Median value and interquartile range (IQR).

be rejected at a $P$ value of $<0.05$. The chi-square test was used to analyze associations between categorical variables. Multiple comparisons of continuous variables were assessed by the Kruskal-Wallis one-way analysis of variance. Receiver operating characteristics (ROC) curve analysis was used to define the diagnostic ability of the various PCT cut-offs, and Youden's indices were calculated to find the best discriminatory cut-off (Youden's index $=$ sensitivity + specificity -1 ). SPSS statistical package, release 13.0 (SPSS Inc., Chicago, IL), was used for all statistical analyses.

2.6. Ethic Statement. Samples were collected as part of standard care and those included in the database were deidentified before access. No personal information was stored in the study database. No patient intervention occurred with the obtained results. For these reasons, the study was exempt from the institutional review board.

\section{Results}

During the entire study period, a total of 8,752 BCs were collected from 3,651 patients. PCT was not drawn concomitantly with the first BCs in 1,702 patients that were excluded from the study. A total of 1,949 patients fulfilled the inclusion criteria and were enrolled in the study. Demographic characteristics of the patients and results from BCs are described in Table 1. Among 586 monomicrobial BCs, 345 (59\%) were positive for Gram-negative, 217 (37\%) for Gram-positive, and $24(4 \%)$ for fungal pathogens. Escherichia coli (183 isolates, $31.2 \%$ ) and Staphylococcus aureus (103 isolates, 17.6\%) were the most frequent isolated organisms.

Antimicrobial therapy was already administered in 79.5\% of patients with negative BCs, $74.6 \%$ with contaminated BCs, $82.6 \%$ with Gram-negative pathogens, $77.5 \%$ with Grampositive pathogens, $87.5 \%$ with fungal pathogens, and $60 \%$ with polymicrobial sepsis. The rates of patients assuming 


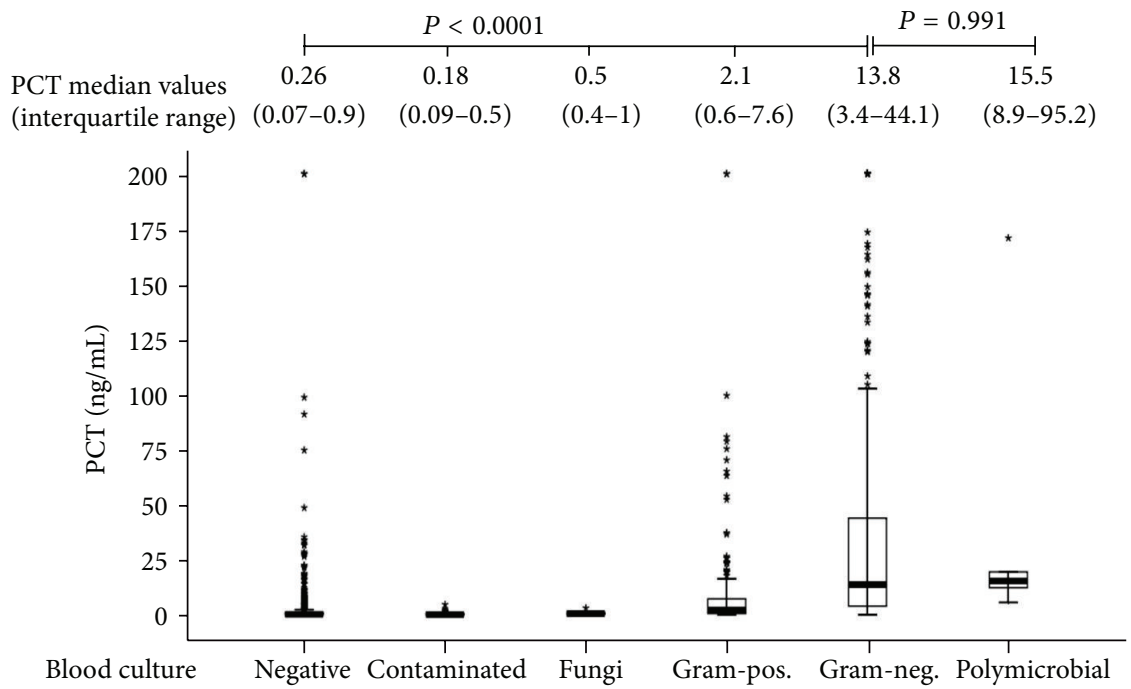

FIGURE 1: Comparison of PCT median values according to BC result.

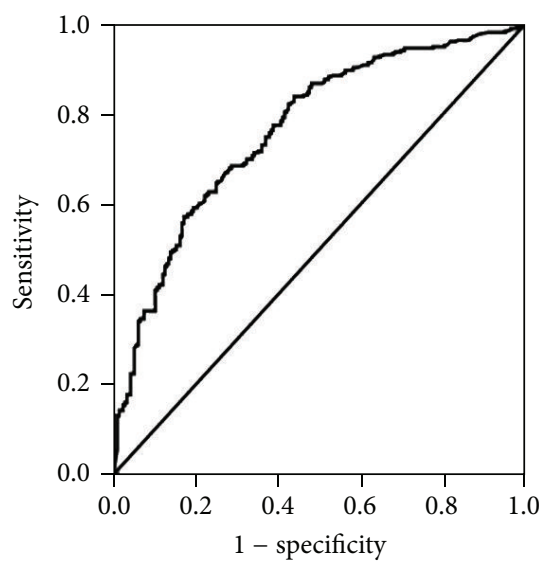

(a) Gram-neg. versus Gram pos

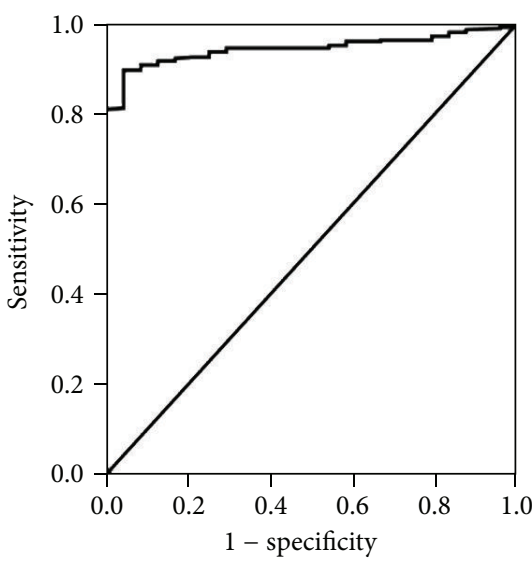

(b) Gram-neg. versus fungi

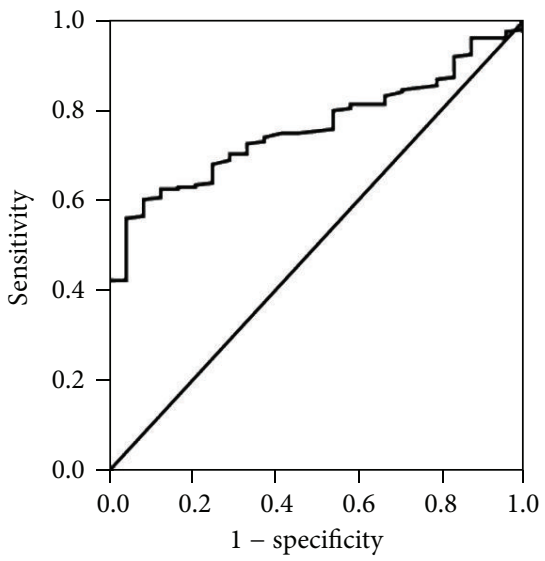

(c) Gram-pos. versus fungi

\begin{tabular}{lccc}
\hline (ROC curve) & $(\mathrm{a})$ & $(\mathrm{b})$ & $(\mathrm{c})$ \\
PCT best cut-off & $10.8 \mathrm{ng} / \mathrm{mL}$ & $1.6 \mathrm{ng} / \mathrm{mL}$ & $1.3 \mathrm{ng} / \mathrm{mL}$ \\
\hline Sensitivity & 0.60 & 0.77 & 0.60 \\
Specificity & 0.82 & 0.96 & 0.92 \\
PPV & 0.84 & 0.99 & 0.98 \\
NPV & 0.57 & 0.22 & 0.20 \\
+LR & 3.42 & 18.3 & 7.55 \\
-LR & 0.48 & 0.24 & 0.43 \\
\hline
\end{tabular}

FIGURE 2: Receiver operating characteristic (ROC) curves of different cut-offs of PCT in differentiating: (a) Gram-negative bacteria from Gram-positive bacteria (AUC 0.765, 95\% CI 0.725-0.805; $P<0.0001$ ); (b) Gram-negative bacteria from fungi (AUC 0.944, 95\% CI 0.919$0.969, P<0.0001$ ); (c) Gram-positive bacteria from fungi (AUC 0.763, 95\% CI 0.693-0.832; $P<0.0001$ ). Sensitivity, Specificity, Positive Predictive Value (PPV), Negative Predictive Value (NPV), Positive Likelihood Ratio (+LR), and Negative Likelihood Ratio (-LR) are reported for the best cut-off values found in each ROC.

antimicrobial therapy according to $\mathrm{BC}$ results showed no significant differences $(P=0.336)$.

PCT median value of positive BCs $(6.72 \mathrm{ng} / \mathrm{mL}$, IQR 1.5-23.3) was significantly higher than those observed in negative BCs $(0.3 \mathrm{ng} / \mathrm{mL}$, IQR $0.1-0.9$, and $P<0.0001)$ or in contaminated BCs $(0.2 \mathrm{ng} / \mathrm{mL}$, IQR $0.1-0.5$, and $P<0.0001)$.

PCT median values according to $\mathrm{BC}$ results are shown in Figure 1. Statistical analysis demonstrated that PCT median value corresponding to $\mathrm{BCs}$ positive for Gram-negative 
TABLE 2: PCT median values corresponding to pathogens that were isolated from two or more patients with monomicrobial bloodstream infections.

\begin{tabular}{|c|c|c|}
\hline Pathogen & Number of patients & Median PCT values (interquartile range) $(\mathrm{ng} / \mathrm{mL})$ \\
\hline \multicolumn{3}{|l|}{ Gram-positives } \\
\hline Staphylococcus aureus & 103 & $3.6(1.3-9.3)$ \\
\hline Enterococcus faecalis & 43 & $0.5(0.3-2.2)$ \\
\hline Enterococcus faecium & 18 & $1.6(0.9-2)$ \\
\hline Streptococcus pneumoniae & 18 & $6.9(3.3-23.9)$ \\
\hline Streptococcus pyogenes & 5 & $2.1(0.2-2.2)$ \\
\hline Streptococcus gallolyticus & 4 & $14(1.6-26.1)$ \\
\hline Listeria monocytogenes & 3 & $1.1(0.6-1.2)$ \\
\hline Streptococcus parasanguinis & 3 & $0.3(0.2-2.7)$ \\
\hline Streptococcus agalactiae & 3 & $1.8(1-7.9)$ \\
\hline Streptococcus mutans & 2 & $6.3(0.6-12.1)$ \\
\hline Streptococcus bovis & 2 & $1.1(0.7-1.4)$ \\
\hline Streptococcus sanguinis & 2 & $5.4(0.1-10.7)$ \\
\hline Propionibacterium acnes & 2 & $0.07(0.05-0.1)$ \\
\hline \multicolumn{3}{|l|}{ Gram-negatives } \\
\hline \multicolumn{3}{|l|}{ Enterobacteriaceae } \\
\hline Escherichia coli & 183 & $18.5(6.5-56.4)$ \\
\hline Klebsiella pneumoniae & 56 & $22.3(9.6-52.4)$ \\
\hline Enterobacter cloacae & 14 & $5.5(3.5-7.5)$ \\
\hline Proteus mirabilis & 12 & $11.3(8.3-16.5)$ \\
\hline Serratia marcescens & 5 & $14.9(3.8-15.5)$ \\
\hline Klebsiella oxytoca & 5 & $2.3(1.1-3.7)$ \\
\hline Salmonella typhi & 3 & $23.2(18-24.7)$ \\
\hline Pantoea agglomerans & 3 & $21.5(12.5-110.7)$ \\
\hline Enterobacter aerogenes & 2 & $71.8(68.2-75.4)$ \\
\hline Citrobacter koseri & 2 & $21(14.4-27.7)$ \\
\hline \multicolumn{3}{|l|}{ Nonfermentative obligate aerobic } \\
\hline Pseudomonas aeruginosa & 21 & $6.8(1.3-11.9)$ \\
\hline Acinetobacter baumannii & 16 & $2.2(0.6-7.4)$ \\
\hline Stenotrophomonas maltophilia & 4 & $20.5(9.4-166.6)$ \\
\hline \multicolumn{3}{|l|}{ Obligate anaerobic } \\
\hline Bacteroides fragilis & 8 & $2.8(0.5-8.5)$ \\
\hline \multicolumn{3}{|l|}{ Fungi } \\
\hline Candida albicans & 12 & $0.5(0.3-1.2)$ \\
\hline Candida parapsilosis & 3 & $0.6(0.5-0.9)$ \\
\hline Candida lusitaniae & 5 & $0.6(0.4-0.7)$ \\
\hline
\end{tabular}

pathogens was significantly higher than those corresponding to negative or contaminated $\mathrm{BCs}$ and to BCs positive for fungal or Gram-positive pathogens, but not to polymicrobial BCs (Figure 1).

To evaluate the PCT diagnostic accuracy in predicting causative organisms of bloodstream infections, ROC analysis was performed in monomicrobial BCs (Figure 2). The best diagnostic accuracy in discriminating Gramnegative from Gram-positive infections was at the cut-off value of $10.8 \mathrm{ng} / \mathrm{mL}$, Gram-negative from fungal infections at $1.6 \mathrm{ng} / \mathrm{mL}$, and Gram-positive from fungal infections at $1.3 \mathrm{ng} / \mathrm{mL}$. The best values were found in discriminating Gram-negative or Gram-positive bacteria from fungi (Figure 2).
Table 2 shows median PCT values corresponding to the different microbial species isolated in two or more patients with monomicrobial bacteremias, and Table 3 reports PCT values corresponding to pathogens isolated only in one patient or to polymicrobial infections. To evaluate the possibility that different PCT values could correspond to different microbial groups, PCT median values obtained in monomicrobial bloodstream infections by different species were compared. Among Gram-positives, median values found for Streptococcus pneumoniae or Staphylococcus aureus were significantly higher than those found for enterococci (0.8 ng/mL, IQR 0.4-2.3, and $P=0.001)$ or streptococci other than S. pneumoniae (1.4 ng/mL, IQR 0.3-3.9, and $P=0.005$ ). No significant difference was found among different yeast 
TABLE 3: PCT values corresponding to pathogens isolated from single patients with monomicrobial or polymicrobial bloodstream infections.

\begin{tabular}{|c|c|c|}
\hline Bloodstream infection from & Pathogen & PCT values $(\mathrm{ng} / \mathrm{mL})$ \\
\hline \multirow{9}{*}{ Gram-positives } & Abiotrophia defectiva & 1.31 \\
\hline & Capnocytophaga canimorsus & 0.87 \\
\hline & Capnocytophaga sputigena & 6.63 \\
\hline & Clostridium paraputrificum & 4.52 \\
\hline & Enterococcus avium & 3.54 \\
\hline & Kytococcus sedentarius & 0.40 \\
\hline & Peptostreptococcus spp. & 0.25 \\
\hline & Streptococcus anginosus & 0.21 \\
\hline & Streptococcus gordonii & 0.45 \\
\hline \multirow{11}{*}{ Gram-negatives } & Acinetobacter junii & 1.70 \\
\hline & Bacteroides thetaiotaomicron & 8.49 \\
\hline & Burkholderia gladioli & 0.42 \\
\hline & Fusobacterium necrophorum & 2.24 \\
\hline & Fusobacterium nucleatum & 0.38 \\
\hline & Haemophilus influenzae & 0.48 \\
\hline & Moraxella catarrhalis & 0.44 \\
\hline & Moraxella nonliquefaciens & 0.98 \\
\hline & Neisseria meningitidis & 24.17 \\
\hline & Providencia rettgeri & 0.90 \\
\hline & Pseudomonas putida & 2.49 \\
\hline \multirow{4}{*}{ Fungi } & Candida glabrata & 0.66 \\
\hline & Candida krusei & 0.72 \\
\hline & Candida pelliculosa & 1.06 \\
\hline & Candida tropicalis & 0.13 \\
\hline \multirow{5}{*}{ Polymicrobial } & Enterococcus faecalis and Serratia marcescens & 15.5 \\
\hline & Enterococcus faecalis and Stenotrophomonas maltophilia & 12.3 \\
\hline & Enterococcus faecium and Klebsiella pneumoniae & 19.5 \\
\hline & Staphylococcus aureus and Acinetobacter baumannii & 5.61 \\
\hline & Staphylococcus aureus and Proteus mirabilis & 170.9 \\
\hline
\end{tabular}

species (data not shown). In bloodstream infections by Gramnegatives, PCT median value corresponding to Enterobacteriaceae (17.1 ng/mL, IQR 5.9-48.5) was significantly higher than that found for nonfermentative $(3.5 \mathrm{ng} / \mathrm{mL}$, IQR $0.8-21.5$, and $P<0.0001)$ or obligate anaerobic bacteria $(2.8 \mathrm{ng} / \mathrm{mL}$, IQR $0.5-8.5$, and $P<0.0001$ ) (Figure 3). ROC analysis showed that the best cut-off for PCT in discriminating Enterobacteriaceae from nonfermentative Gram-negative bacteria was $3.1 \mathrm{ng} / \mathrm{mL}$, with 90\% sensitivity and 91\% PPV (Figure 4).

\section{Discussion}

The main findings of this study are that, in patients with suspected sepsis, the PCT cut-off value of $10.8 \mathrm{ng} / \mathrm{mL}$ could be of help in predicting an infection caused by Gram-negatives, with a specificity of $82.5 \%$. A cut-off of $3.1 \mathrm{ng} / \mathrm{mL}$ could be of help in excluding an infection caused by Enterobacteriaceae but not by nonfermentative Gram-negatives, with a sensitivity of $90.1 \%$. These results suggest that PCT could be of some help to clinicians in evaluating the more appropriate initial antimicrobial therapy in the cases in which, even if informed of the presence of Gram-negative bacilli in

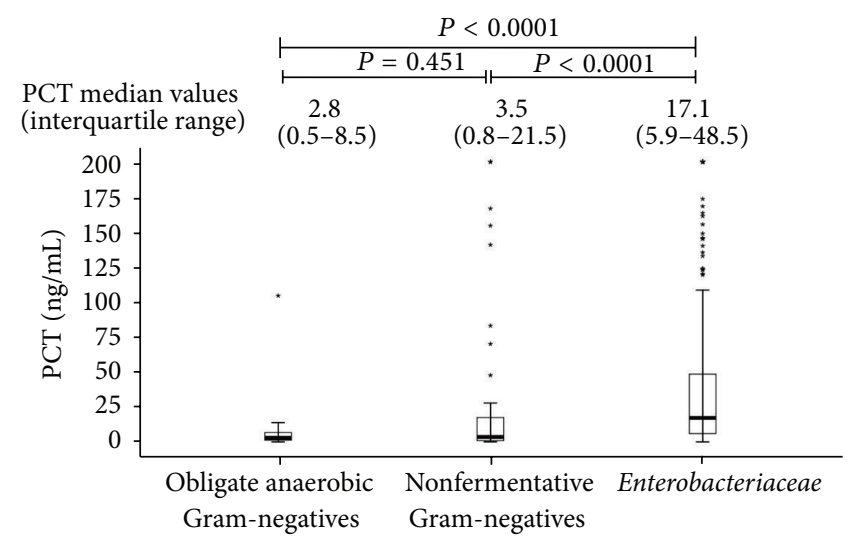

FIGURE 3: Comparison of PCT median values in bloodstream infections by Enterobacteriaceae, non-fermentative Gram-negative bacteria, or obligate anaerobic Gram-negative bacteria.

patients' BC, they have to wait further 24-48 hours for species identification. This could be a relevant issue given 


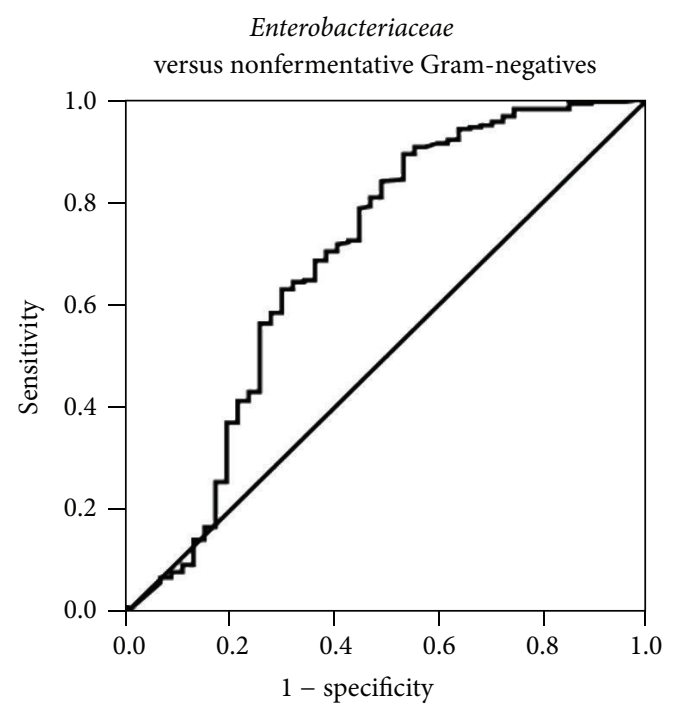

\begin{tabular}{lllllll}
\hline $\begin{array}{l}\text { PCT cut-off } \\
\text { value }(\mathrm{ng} / \mathrm{mL})\end{array}$ & Sensitivity & Specificity & PPV & NPV & $+\mathrm{LR}$ & $-\mathrm{LR}$ \\
\hline 0.05 & 1.00 & 0.00 & 0.85 & 0.00 & 1.00 & 0.00 \\
0.10 & 0.99 & 0.06 & 0.86 & 0.50 & 1.05 & 0.16 \\
0.25 & 0.99 & 0.13 & 0.87 & 0.65 & 1.13 & 0.07 \\
0.50 & 0.98 & 0.17 & 0.87 & 0.61 & 1.18 & 0.11 \\
1.00 & 0.97 & 0.25 & 0.89 & 0.57 & 1.29 & 0.12 \\
2.00 & 0.92 & 0.36 & 0.90 & 0.42 & 1.43 & 0.22 \\
3.10 & 0.90 & 0.46 & 0.91 & 0.43 & 1.66 & 0.21 \\
5.00 & 0.77 & 0.55 & 0.91 & 0.28 & 1.71 & 0.41 \\
10.00 & 0.62 & 0.68 & 0.92 & 0.22 & 1.93 & 0.55 \\
25.00 & 0.38 & 0.78 & 0.92 & 0.17 & 1.72 & 0.79 \\
50.00 & 0.25 & 0.83 & 0.89 & 0.15 & 1.47 & 0.90 \\
100.00 & 0.13 & 0.87 & 0.86 & 0.14 & 1.00 & 1.00 \\
\hline & & & & & &
\end{tabular}

FIGURE 4: Receiver operating characteristic (ROC) curve of different cut-offs of PCT in differentiating Enterobacteriaceae from nonfermentative Gram-negative bacteria (AUC 0.691, 95\% CI $0.593-0.789, P<0.0001$ ). Sensitivity, specificity, positive predictive value (PPV), negative predictive value (NPV), positive likelihood ratio (+LR), and negative likelihood ratio ( $-\mathrm{LR})$ of different cut-off values are reported.

that, in bloodstream infections by antibiotic-resistant nonfermentative Gram-negatives, such as Pseudomonas aeruginosa, an inappropriate initial antimicrobial therapy is strongly associated with adverse outcome $[11,12]$.

The ability of PCT to discriminate infections by Grampositive or Gram-negative organisms has been recently described. Charles et al. [14], in a retrospective study on 97 bacteremia episodes, found that serum PCT levels were markedly greater for Gram-negatives than for Grampositives, with an AUC of 0.79. Similarly, Koivula et al. [15] showed that elevated levels of PCT within 24 hours after the onset of fever predict Gram-negative bacteremia in hematological patients. Brodská et al. [13] in a retrospective study evaluating 166 patients found that PCT cut-off of $15 \mathrm{ng} / \mathrm{mL}$ can discriminate between sepses caused by Gram-negative bacteria or by Gram-positives and fungi, with a specificity of $87.8 \%$. The different cut-off found in this study may be due to its greater sample size, with fourfold Acinetobacter baumannii and nearly threefold Pseudomonas aeruginosa isolates, associated with lower median PCT values, and to its prospective nature, limiting possible selection bias.

Although the mechanism underlying different PCT production in response to different bacterial pathogens is not completely clear, it could possibly be explained by the different interaction of Gram-positive or Gram-negative bacteria with host's cells, involving lipoteichoic acids or LPS, respectively, and different pathogen-associated molecular patterns (PAMPs), engaging different TLRs, expressed on human cells [7]. In particular, Gram-positive bacteria activate the TLR2 pathway $[20,21]$, whereas Gram-negative bacteria the TLR4 pathway [22], resulting in different production of inflammatory cytokines, such as interleukin- $1 \beta$, interleukin-6 (IL6 ), and tumor necrosis factor- $\alpha$, that ultimately stimulate ubiquitous transcription of calcitonin-mRNA and release of PCT from multiple tissues throughout the body $[1,23]$.

To the best of our knowledge, this is the first study showing a significant difference in the PCT values between bloodstream infections sustained by Enterobacteriaceae and those caused by nonfermentative Gram-negatives. Interestingly, ROC analysis suggests that although PCT values $>3.1 \mathrm{ng} / \mathrm{mL}$ do not discriminate between the two groups of pathogens, values $\leq 3.1 \mathrm{ng} / \mathrm{mL}$ are indicative of a low probability of bloodstream infection by Enterobacteriaceae. These results are in line with the findings of Elson et al. [24], demonstrating that Enterobacteriaceae such as Escherichia coli and Klebsiella pneumoniae, at a concentration of $10^{4}$ cells $/ \mathrm{mL}$, induced a greater in vitro IL-6 production by human umbilical vein endothelial cells than $P$. aeruginosa that, even at a concentrations of $10^{6}$ cells $/ \mathrm{mL}$, produced low levels of IL-6, a known inducer of PCT [23].

It is conceivable that the high median PCT values found in polymicrobial bloodstream infections could be attributable to the presence of Gram-negative bacteria in all of them, specifically, Enterobacteriaceae in three out of five cases, but this issue needs to be verified with further studies.

We found that PCT optimally discriminated between Gram-negative and fungal infections at the best cut-off of $1.6 \mathrm{ng} / \mathrm{mL}$ and, though with less accuracy, between Grampositive and fungal infections. Similarly, Martini et al. [25] in 48 critically ill surgical patients at high risk for fungal infection with signs of sepsis found that PCT cut-off of $2.0 \mathrm{ng} / \mathrm{mL}$ can discriminate between Candida and bacterial sepsis. Conversely, $\mathrm{Fu}$ et al. [26], in a population of 85 critically ill patients, found a cut-off of $8.06 \mathrm{ng} / \mathrm{mL}$ in discriminating between candidemia and Gram-negative bacterial sepsis. These differences highlight how the results can greatly 
depend on the type of the studied patients population, as PCT values can significantly differ in different clinical settings [27]. Indeed, the present study was carried out in a large population of 1,949 patients mainly from internal medicine wards, for which blood cultures were collected together with sera for PCT determination. These inclusion criteria could have selected patients with high suspicion of sepsis, as evidenced by the high pathogen detection rate (30.3\%) found.

This study has some limitations. First, the discriminatory power found for PCT could have been confounded by the lack of patients' baseline characteristics and comorbidities. Indeed, information about factors that can influence PCT levels, such as recent transplantation, severe and prolonged cardiogenic shock, heat shock, severe pancreatitis, rhabdomyolysis, autoimmune disorders, and others [28], was not available for all the patients. Second, since the study has been conducted in a wide range of patients, the results are not specifically applicable to selected settings. Third, as intervals between the onset of symptoms and sampling were not available, it was not possible to rule out that some low PCT values could have been due to early sampling, given that PCT increases during the first six hours of infection $[29,30]$. Finally, the low number of bacteremias from rarely encountered pathogens does not allow any conclusion about the significance of PCT in these infections (Table 3). Nevertheless, the large cohort studied, the systematic approach to PCT measurement, the fact that all the bloodstream infections included in the study were microbiologically documented, and that the spectrum of causative organisms was consistent with a large prospective multicenter Italian study, with E. coli and $S$. aureus as the most frequent pathogens [31], could have strengthened the results of this study.

\section{Conclusions}

In conclusion, PCT may be of value to distinguish Gramnegative from Gram-positive and fungal infections; nevertheless, its utility to predict different microorganisms needs to be assessed in further studies including detailed patient information. The findings of the present study show that PCT cut-off of $\geq 10.8 \mathrm{ng} / \mathrm{mL}$ could suggest an infection by Gramnegatives, and the cut-off $\leq 3.1 \mathrm{ng} / \mathrm{mL}$ could suggest exclusion of infection by Enterobacteriaceae. A PCT cut-off $>1.3 \mathrm{ng} / \mathrm{mL}$ could be of help in ruling out a fungal bloodstream infection.

\section{Conflict of Interests}

The authors declare that there is no conflict of interests regarding the publication of this paper.

\section{References}

[1] S. Y. Cho and J. H. Choi, "Biomarkers of sepsis," Infection \& Chemotherapy, vol. 46, no. 1, pp. 1-12, 2014.

[2] M. Christ-Crain and B. Müller, "Procalcitonin in bacterial infections-hype, hope, more or less?" Swiss Medical Weekly, vol. 135, no. 31-32, pp. 451-460, 2005.

[3] P. Schuetz, P. Maurer, V. Punjabi, A. Desai, D. N. Amin, and E. Gluck, "Procalcitonin decrease over 72 hours in US critical care units predicts fatal outcome in sepsis patients," Critical Care, vol. 17, no. 3, article R115, 2013.

[4] L. Simon, F. Gauvin, D. K. Amre, P. Saint-Louis, and J. Lacroix, "Serum procalcitonin and C-reactive protein levels as markers of bacterial infection: a systematic review and meta-analysis," Clinical Infectious Diseases, vol. 39, no. 2, pp. 206-217, 2004.

[5] P. Schuetz, B. Mueller, and A. Trampuz, "Serum procalcitonin for discrimination of blood contamination from bloodstream infection due to coagulase-negative staphylococci," Infection, vol. 35, no. 5, pp. 352-355, 2007.

[6] W. Shomali, R. Hachem, A.-M. Chaftari et al., "Can procalcitonin differentiate Staphylococcus aureus from coagulasenegative staphylococci in clustered gram-positive bacteremia?" Diagnostic Microbiology \& Infectious Disease, vol. 76, no. 2, pp. 158-161, 2013.

[7] S. Kumar, H. Ingle, D. V. R. Prasad, and H. Kumar, "Recognition of bacterial infection by innate immune sensors," Critical Reviews in Microbiology, vol. 39, no. 3, pp. 229-246, 2013.

[8] R. P. Dellinger, M. M. Levy, A. Rhodes et al., "Surviving sepsis campaign: international guidelines for management of severe sepsis and septic shock, 2012," Intensive Care Medicine, vol. 39, no. 2, pp. 165-228, 2013.

[9] R. Khatib, S. Saeed, M. Sharma, K. Riederer, M. G. Fakih, and L. B. Johnson, "Impact of initial antibiotic choice and delayed appropriate treatment on the outcome of Staphylococcus aureus bacteremia," European Journal of Clinical Microbiology \& Infectious Diseases, vol. 25, no. 3, pp. 181-185, 2006.

[10] S.-H. Kim, W.-B. Park, C.-S. Lee et al., "Outcome of inappropriate empirical antibiotic therapy in patients with Staphylococcus aureus bacteraemia: analytical strategy using propensity scores," Clinical Microbiology and Infection, vol. 12, no. 1, pp. 13-21, 2006.

[11] C.-I. Kang, S.-H. Kim, B. P. Wan et al., "Bloodstream infections caused by antibiotic-resistant gram-negative bacilli: risk factors for mortality and impact of inappropriate initial antimicrobial therapy on outcome," Antimicrobial Agents and Chemotherapy, vol. 49, no. 2, pp. 760-766, 2005.

[12] S. T. Micek, E. C. Welch, J. Khan et al., "Resistance to empiric antimicrobial treatment predicts outcome in severe sepsis associated with gram-negative bacteremia," Journal of Hospital Medicine, vol. 6, no. 7, pp. 405-410, 2011.

[13] H. Brodská, K. Malíčková, V. Adámková, H. Benáková, M. M. Šåastná, and T. Zima, "Significantly higher procalcitonin levels could differentiate Gram-negative sepsis from Gram-positive and fungal sepsis," Clinical \& Experimental Medicine, vol. 13, no. 3, pp. 165-170, 2013.

[14] P. E. Charles, S. Ladoire, S. Aho et al., "Serum procalcitonin elevation in critically ill patients at the onset of bacteremia caused by either gram negative or gram positive bacteria," BMC Infectious Diseases, vol. 8, article 38, 2008.

[15] I. Koivula, S. Hämäläinen, E. Jantunen et al., "Elevated procalcitonin predicts Gram-negative sepsis in haematological patients with febrile neutropenia," Scandinavian Journal of Infectious Diseases, vol. 43, no. 6-7, pp. 471-478, 2011.

[16] R. C. Bone, R. A. Balk, F. B. Cerra et al., "Definitions for sepsis and organ failure and guidelines for the use of innovative therapies in sepsis. The ACCP/SCCM consensus conference committee. American College of Chest Physicians/Society of Critical Care Medicine," Chest, vol. 101, no. 6, pp. 1644-1655, 1992.

[17] M. Pammi, D. Zhong, Y. Johnson, P. Revell, and J. Versalovic, "Polymicrobial bloodstream infections in the neonatal intensive 
care unit are associated with increased mortality: a case-control study," BMC Infectious Diseases, vol. 14, no. 1, article 390, 2014.

[18] D. J. Diekema, S. E. Beekmann, K. C. Chapin, K. A. Morel, E. Munson, and G. V. Doern, "Epidemiology and outcome of nosocomial and community-onset bloodstream infection," Journal of Clinical Microbiology, vol. 41, no. 8, pp. 3655-3660, 2003.

[19] M. P. Weinstein, "Blood culture contamination: persisting problems and partial progress," Journal of Clinical Microbiology, vol. 41, no. 6, pp. 2275-2278, 2003.

[20] H. Echchannaoui, K. Frei, C. Schnell, S. L. Leib, W. Zimmerli, and R. Landmann, "Toll-like receptor 2-deficient mice are highly susceptible to Streptococcus pneumoniae meningitis because of reduced bacterial clearing and enhanced inflammation," The Journal of Infectious Diseases, vol. 186, no. 6, pp. 798806, 2002.

[21] O. Takeuchi, K. Hoshino, T. Kawai et al., "Differential roles of TLR2 and TLR4 in recognition of gram-negative and grampositive bacterial cell wall components," Immunity, vol. 11, no. 4, pp. 443-451, 1999.

[22] A. Poltorak, X. He, I. Smirnova et al., "Defective LPS signaling in $\mathrm{C} 3 \mathrm{H} / \mathrm{HeJ}$ and $\mathrm{C} 57 \mathrm{BL} / 10 \mathrm{ScCr}$ mice: mutations in Tlr4 gene," Science, vol. 282, no. 5396, pp. 2085-2088, 1998.

[23] B. Müller, J. C. White, E. S. Nylén, R. H. Snider, K. L. Becker, and J. F. Habener, "Ubiquitous expression of the calcitonin-I gene in multiple tissues in response to sepsis," The Journal of Clinical Endocrinology \& Metabolism, vol. 86, no. 1, pp. 396-404, 2001.

[24] G. Elson, I. Dunn-Siegrist, B. Daubeuf, and J. Pugin, "Contribution of toll-like receptors to the innate immune response to Gram-negative and Gram-positive bacteria," Blood, vol. 109, no. 4, pp. 1574-1583, 2007.

[25] A. Martini, L. Gottin, N. Menestrina, V. Schweiger, D. Simion, and J.-L. Vincent, "Procalcitonin levels in surgical patients at risk of candidemia," The Journal of Infection, vol. 60, no. 6, pp. 425-430, 2010.

[26] Y. Fu, J. Chen, B. Cai et al., "The use of PCT, CRP, IL-6 and SAA in critically ill patients for an early distinction between candidemia and Gram positive/negative bacteremia," Journal of Infection, vol. 64, no. 4, pp. 438-440, 2012.

[27] P. Schuetz, W. Albrich, and B. Mueller, "Procalcitonin for diagnosis of infection and guide to antibiotic decisions: past, present and future," BMC Medicine, vol. 9, article 107, 2011.

[28] M. Meisner, "Update on procalcitonin measurements," Annals of Laboratory Medicine, vol. 34, no. 4, pp. 263-273, 2014.

[29] P. Dandona, D. Nix, M. F. Wilson et al., "Procalcitonin increase after endotoxin injection in normal subjects," Journal of Clinical Endocrinology and Metabolism, vol. 79, no. 6, pp. 1605-1608, 1994.

[30] M. Limper, M. D. de Kruif, A. J. Duits, D. P. M. Brandjes, and E. C. M. van Gorp, "The diagnostic role of Procalcitonin and other biomarkers in discriminating infectious from non-infectious fever," The Journal of Infection, vol. 60, no. 6, pp. 409-416, 2010.

[31] F. Luzzaro, G. Ortisi, M. Larosa, M. Drago, G. Brigante, and G. Gesu, "Prevalence and epidemiology of microbial pathogens causing bloodstream infections: results of the OASIS multicenter study," Diagnostic Microbiology and Infectious Disease, vol. 69, no. 4, pp. 363-369, 2011. 


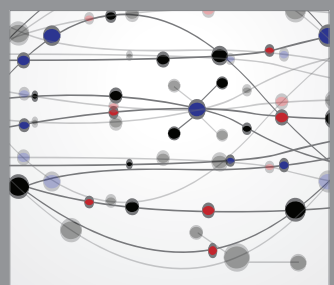

The Scientific World Journal
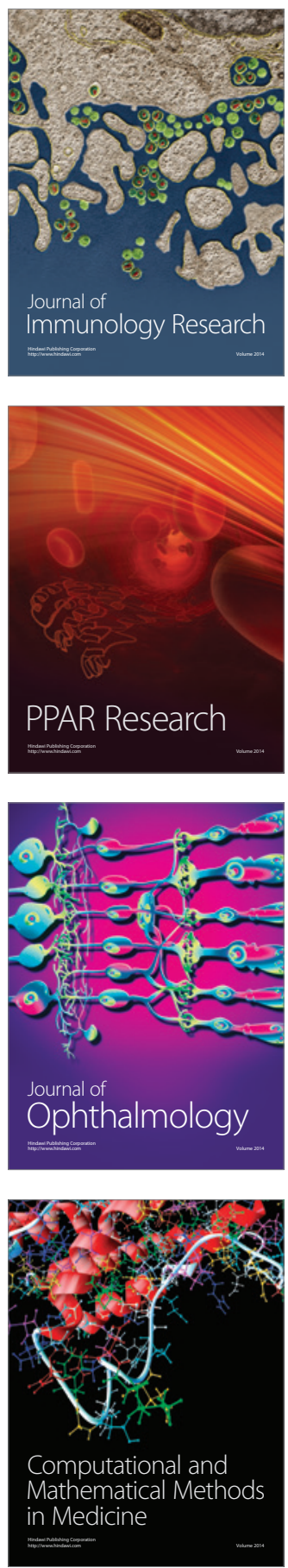

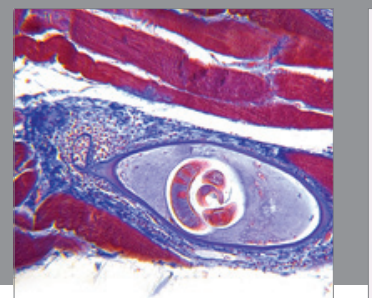

Gastroenterology

Research and Practice
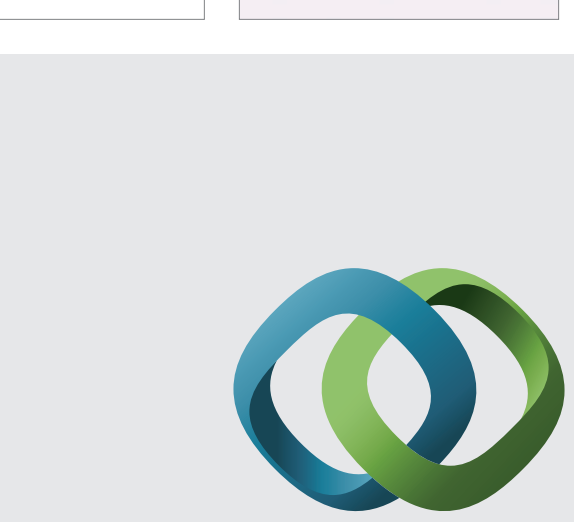

\section{Hindawi}

Submit your manuscripts at

http://www.hindawi.com
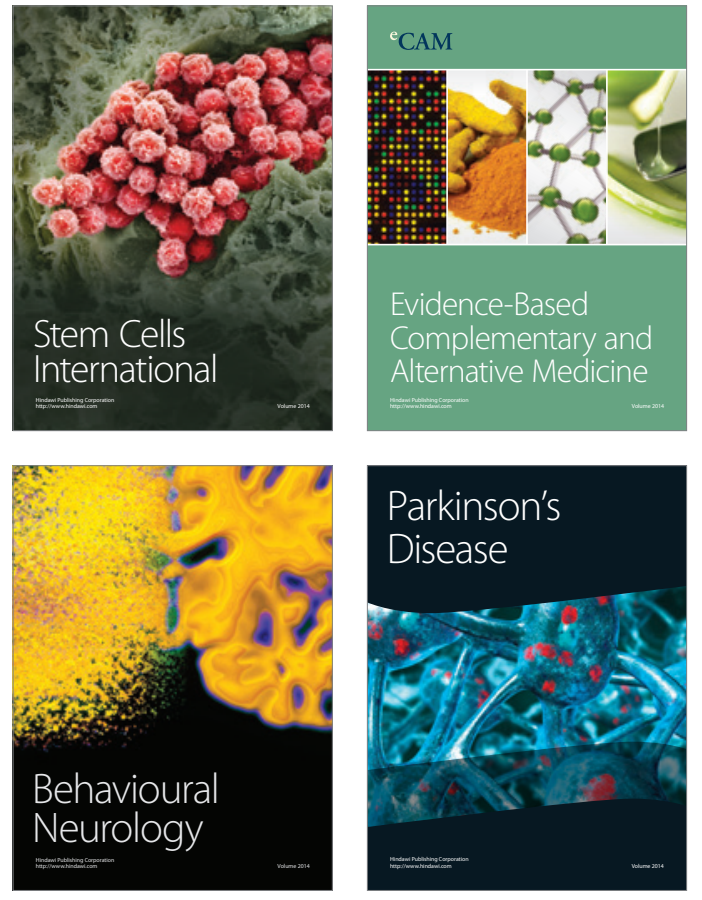
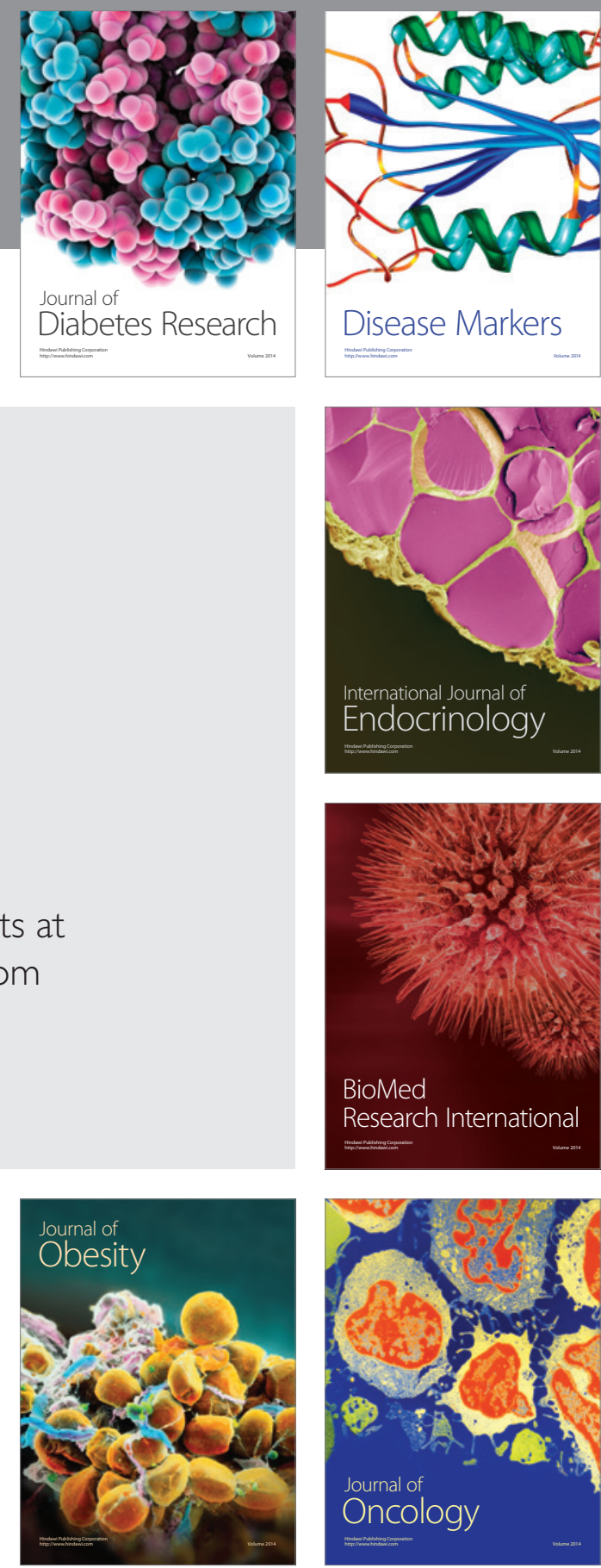

Disease Markers
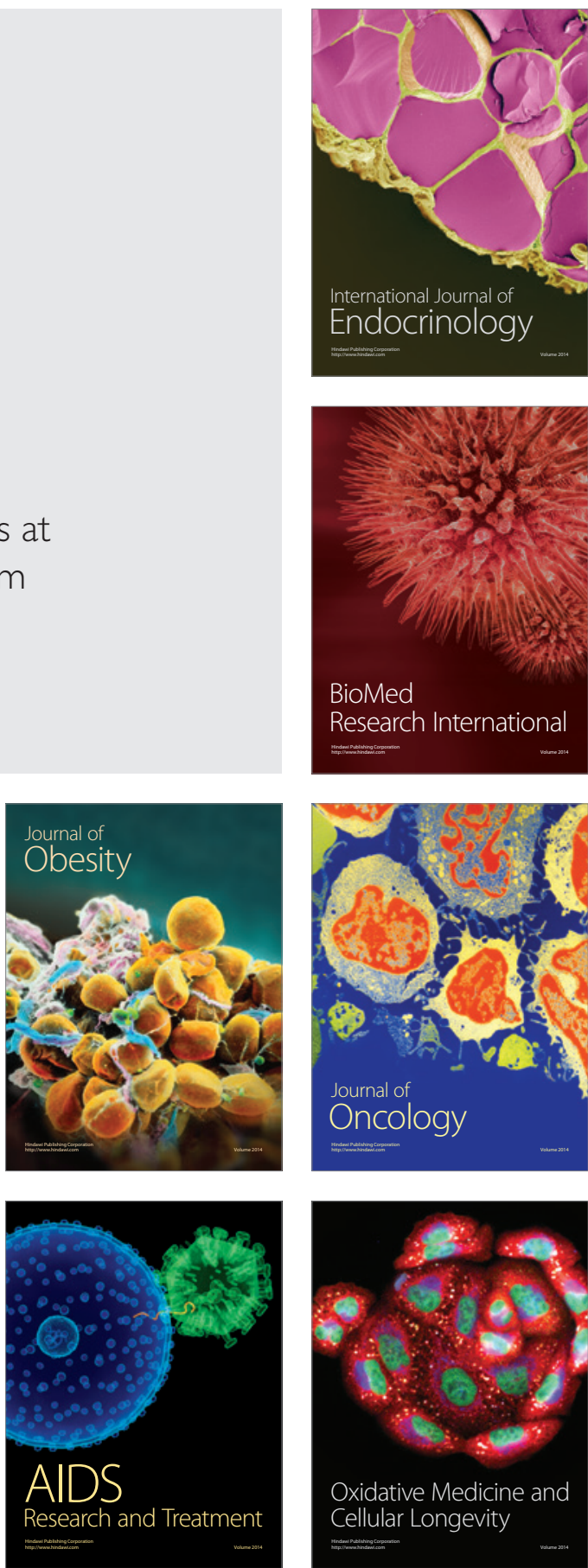